\title{
NOBLE HALLS OF DISCOVERY
}

\section{Gakushuin University is the top-ranking institution when assessed on the quality of its research in the natural sciences.}

\section{BY TIM HORNYAK}

$\mathrm{G}$ akushuin University takes great pride in its pedigree. Established in Kyoto in 1847 to educate Japan's nobility, its forerunner, Gakushuin School, was relocated to Tokyo 30 years later, but only opened its doors to the general public as a university after World War II.

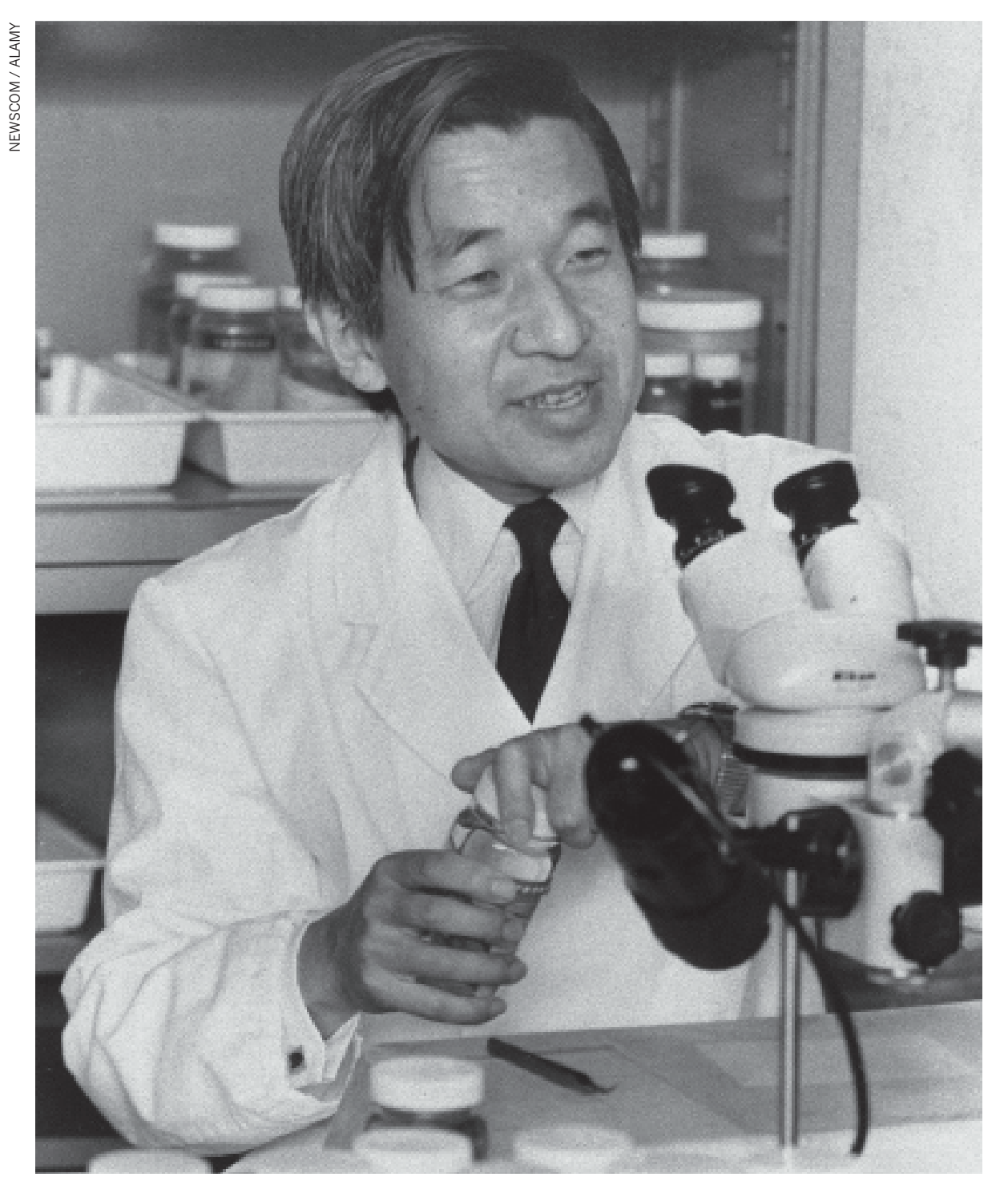

Emperor Akihito in 1982, then Crown Prince. Akihito was a taxonomic researcher of gobioid fish, and is among many alumni of note from the prestigious Gakushuin University.

The university's alumni include artists such as Yoko Ono, animé legend Hayao Miyazaki, and numerous politicians, as well as Japan's 84-year-old emperor, Akihito. The scientifically minded monarch has a deep interest in fish and has written extensively about the classification of gobies.

Gakushuin ranks first among all Japanese universities in the Nature Index for its his work. "I would never be able to maintain
this style if I had moved to one of the major national universities," he says. -

high-quality research output relative to its total number of natural science articles in the Scopus database. To achieve this, between 2012 and 2017, the university accrued a weighted fractional count of 42 for its authorship of papers in the index, out of 452 natural science papers tracked by Scopus.

The university's biggest strength is in chemistry, with some notable contributions to the physical and life sciences as well. In 2013, biologist Kiyokazu Agata and colleagues elucidated the signaling pathways involved in the flatworm's ability to regenerate tissue an entire organism can grow out of the fragment of a tail. In 2017, biophysicists, Daisuke Nakane and Takayuki Nishizaka discovered that the hair-like appendages that blue-green bacteria use to propel themselves protrude in response to blue light.

\section{"I WOULD NEVER BE ABLE TO MAINTAIN THIS STYLE IF I HAD MOVED TO ONE OF THE MAJOR NATIONAL UNIVERSITIES."}

And in 2016, theoretical physicist Hal Tasaki co-authored a paper in Physical Review Letters on the fundamental relationship between power and efficiency of heat engines. A paper Tasaki published in the same journal in 1998 on the derivation of statistical mechanics based entirely on quantum mechanics went unnoticed for nearly a decade. It has since been recognized as a seminal work in the field.

Tasaki attributes Gakushuin's success to an environment that fosters curiosity for curiosity's sake. In the 30 years that he has been at the physics department, Tasaki says that he never felt pressured to publish lots of papers in high-impact journals. "Instead, I was told by older professors that we must spend a long time to accomplish something important." He would sometimes go years without publishing 